\title{
Association of Estimated Plasma Volume Status with Hemodynamic and Echocardiographic Parameters
}

Masatake Kobayashi ${ }^{1}$, Olivier Huttin ${ }^{1}$, Erwan Donal ${ }^{2,3,4}$, Kevin Duarte ${ }^{1}$, Arnaud Hubert ${ }^{2,3,4}$, Hervé Le Breton ${ }^{2,3,4}$, Elena Galli ${ }^{2,3,4}$, Maxime Fournet ${ }^{2,3,4}$, Philippe Mabo ${ }^{2,3,4}$, Frederic Schnell ${ }^{2,3,5}$, Christophe Leclercq ${ }^{2,3,4}$, Patrick Rossignol ${ }^{1}$, Nicolas Girerd ${ }^{1}$

1. Université de Lorraine, INSERM, Centre d'Investigations Cliniques 1433, CHRU de Nancy, Inserm 1116 and INI-CRCT (Cardiovascular and Renal Clinical Trialists) F-CRIN Network, Nancy, France.

2. CHU Rennes, Service de Cardiologie et Maladies Vasculaires et CIC-IT 1414, Rennes, 35000, France

3. Université de Rennes 1, LTSI, Rennes, 35000, France

4. INSERM, U1099, Rennes, 35000, France

5. CHU Rennes, Service de Médicine du Sport, Rennes, 35000, France

\section{Corresponding Author:}

Pr. Nicolas Girerd

Centre d'Investigation Clinique Pierre Drouin -INSERM - CHRU de Nancy, Institut lorrain du cœur et des, vaisseaux Louis Mathieu, Nancy, France

Address : 4, rue du Morvan. 54500 Vandoeuvre-Les-Nancy

E-mail: n.girerd@chru-nancy.fr

Total number of tables and figures: tables 2 figures 2

Short title: Association between plasma volume and congestion markers

Keywords: Plasma volume, congestion, left ventricular filling pressure, sex difference

Conflict of interest: None 


\begin{abstract}
Background: Estimated plasma volume status (ePVS) has diagnostic and prognostic value in patients with heart failure (HF). However, it remains unclear which congestion markers (i.e., biological, imaging and hemodynamic markers) are preferentially associated with ePVS. In addition, there is evidence of sex differences in both the hematopoietic process and myocardial structure/function.
\end{abstract}

Method and results: Patients with significant dyspnea $(\mathrm{NYHA} \geq 2)$ underwent echocardiography and lung ultrasound within four hours prior to cardiac catheterization. Patients were divided according to tertiles based on sex-specific ePVS thresholds calculated from hemoglobin and hematocrit measurements using Duarte’s formula.

Among the 78 included patients (median age 74.5 years; males 69.2\%; HF 48.7\%), median ePVS was 4.1 (percentile $\left.{ }_{25-75}=3.7-4.9\right) \mathrm{ml} / \mathrm{g}$ in males $(\mathrm{N}=54)$ and $4.8(4.4-5.3) \mathrm{ml} / \mathrm{g}$ in females $(\mathrm{N}=24)$. Patients with the highest ePVS had more frequently HF, higher NT-proBNP, larger left atrial volume and higher E/e' (all p-values $<0.05$ ), but no difference in inferior vena cava diameter or pulmonary congestion assessed by lung ultrasound (all p-values $>0.10$ ). In multivariable analysis, higher E/e' and lower diastolic blood pressure were significantly associated with increased ePVS. The association between ePVS and congestion variables was not sex-dependent except for left ventricular enddiastolic pressure, which was only correlated with ePVS in females (Spearman Rho=0.53, $\mathrm{p}<0.01$ in females and

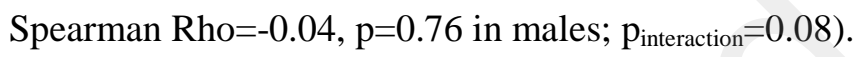

Conclusion: ePVS is associated with E/e' regardless of sex, while only associated with invasively measured left ventricular end-diastolic pressure in females. These results suggest that ePVS is preferably associated with left-sided hemodynamic markers of congestion. 


\section{Introduction}

Plasma volume is a marker of volume overload and is linked to the regulation between interstitial and intravascular spaces ${ }^{1,2}$. Estimated plasma volume status (ePVS) derived from hemoglobin and hematocrit has been repeatedly reported to be associated with clinical outcomes in patients with acute or chronic heart failure (HF) ${ }^{3-6}$. Previous reports showed only a moderate association between ePVS using various equations and radiotracer-based quantitative plasma volume measurements ${ }^{4,7,8}$. However, the correlation between PV estimated from hemoglobin/hematocrit and measured PV by 125I-human serum albumin in diabetic patients was recently showed to be acceptable (concordance index 0.6, $\mathrm{P}<0.01)^{9}$. There are only sparse data however regarding the association of ePVS with clinical, biological and echocardiographic congestion as well as with invasive hemodynamic parameters ${ }^{5,6,10-12}$. Whether ePVS is more closely associated with pulmonary or systemic congestion markers has yet to be ascertained.

In addition, current evidence suggests that there are underlying sex differences in hematopoiesis ${ }^{13}$, myocardial structure and function ${ }^{14,15}$. These sex differences may have a substantial impact on the appropriate ePVS thresholds. However, whether the association between congestion markers and ePVS is sex-dependent remains to be established.

The present study aimed to investigate 1) the association of ePVS with clinical, biological, echocardiographic as well as invasive hemodynamic congestion variables and 2) whether these associations are sex-dependent.

\section{Methods}

\section{Patient Population}

This study prospectively included 81 patients with significant dyspnea (NYHA $\geq \mathrm{II})$ who underwent a coronary angiography with left heart catheterization (LHC) between May 2016 and July $2017{ }^{16}$. Seventy-eight patients who had available hemoglobin/hematocrit data were included in this subsequent analysis. Exclusion criteria were: mitral stenosis, known pulmonary fibrosis, pneumonia, active lung cancer and history of recent chest trauma. Demographic characteristics, comorbidities and biological profiles were obtained from review of medical records. HF was diagnosed according to the ESC guidelines ${ }^{17}$. Estimated glomerular filtration rate (eGFR) was calculated by the Chronic Kidney Disease Epidemiology Collaboration formula ${ }^{18}$. The study protocol was approved by the local ethics committee (authorization number: 2014-A01331-456).

\section{Transthoracic Echocardiography}


All patients underwent a standard echocardiography using a Vivid S6, E7 or E9 ultrasound system (General Electric Healthcare, Horten, Norway). Images were recorded on a remote station for off-line analysis using a dedicated software (EchoPAC PC, version BT 13, General Electric Healthcare, Horten, Norway). Interpretation was blinded for clinical and hemodynamic data. Left ventricular ejection fraction (LVEF) was measured using the biplane Simpson's method ${ }^{19}$. Diastolic function was assessed from the pattern of mitral inflow by pulsed-wave Doppler. Mitral annular early diastolic velocity (e') was assessed at the septal and lateral sites of the mitral annulus using tissue Doppler imaging. E/A ratio, e’ mean and E/e’ mean ratio were calculated. Inferior vena cava (IVC), tricuspid annulus plane systolic excursion and left atrial volume (LAV) were obtained as recommended ${ }^{19}$. Pulmonary arterial systolic pressure was estimated using tricuspid velocity and inferior vena cava compliance and diameter ${ }^{19}$. Right ventricular (RV) function was assessed according to recent guidelines ${ }^{19}$.

\section{Hemodynamic Data and Lung Ultrasonography}

LHC was performed within four hours following echocardiography. Prior to coronary angiography, transducers were calibrated, with a 0-level set at the mid-axillary line. The left ventricular end-diastolic pressure (LVEDP) was continuously recorded (25 mm/s) with a 5 French Judkin R4 catheter (ICU Medical, San Clemente, CA, USA) placed at the mid-LV cavity. Waveform analysis was blinded from clinical and echocardiographic data. LVEDP was calculated as the mean value of 4 consecutive heart cycles.

Lung ultrasound was performed immediately before echocardiography with patients in supine or near-tosupine position, as previously described ${ }^{20}$. Loops were stored on a remote station for off-line analysis using the same tools as those used for echocardiography. For each lung ultrasound zone, the number of B-lines was quantified from 0 to 10, with resulting LUS scoring ranging from 0 to 80 (8-zone method). An excellent reproducibility of measurements, performed by experienced cardiologists, has previously been reported in this population ${ }^{16}$.

\section{Estimated Plasma Volume Status}

ePVS was calculated from the Strauss-derived Duarte formula using hematocrit and hemoglobin values ${ }^{3}$ as follows: ePVS $(\mathrm{mL} / \mathrm{g})=100 \times(1$-hematocrit $) /$ hemoglobin in $\mathrm{g} / \mathrm{dL}$

The Hakim formula was also used for calculating plasma volume estimation derived from hematocrit and dry body weight using the following equations ${ }^{21}$ : 
Actual plasma volume $=(1$ - hematocrit $) \times(\mathrm{a}+\mathrm{b} \times$ body weight in $\mathrm{kg})$

Ideal plasma volume $=\mathrm{c} \times$ body weight in $\mathrm{kg}$

(males: $\mathrm{a}=1530, \mathrm{~b}=41.0, \mathrm{c}=39$; females; $\mathrm{a}=864, \mathrm{~b}=47.9, \mathrm{c}=40$ ),

ePVS=[(actual plasma volume - ideal plasma volume)/ideal plasma volume $] \times 100$.

\section{Statistical Analysis}

Continuous data are expressed as median (25 and 75 percentile) and categorical data as numbers (\%). Patients were divided into three groups according to sex-specific ePVS tertiles [median (IQR) = 4.07 (3.73-4.93) $\mathrm{ml} / \mathrm{g}$ in males and 4.76 (4.37-5.27) $\mathrm{ml} / \mathrm{g}$ in females]. Group differences were assessed using Kruskal-Wallis tests for continuous variables and $\chi^{2}$ tests or Fisher's exact test for categorical variables. Unadjusted correlations were expressed using Spearman's correlation coefficients.

Linear regression analyses were performed to evaluate the association of ePVS with clinical, biological, echocardiographic and invasive hemodynamic variables. All variables with a $\mathrm{P}<0.10$ in univariable analysis were used as candidate variables in the multivariable model prior to backward selection procedures. An interaction test was performed to determine whether the associations between ePVS and congestion markers are sex-dependent.

Statistical analyses were performed using R version 3.4.0 (R Development Core Team, Vienna, Austria). A two-sided $\mathrm{p}$-value $<0.05$ for associations and $\mathrm{p}<0.10$ for interactions were considered statistically significant.

\section{Results}

\section{Baseline Characteristics according to Renin and Aldosterone Levels}

Among the 78 patients included in this study, 54\% were male, median age was 74.5 (67.0-80.0) years, one-fifth (21.8 $\%$ ) of the population had a BMI $\geq 30 \mathrm{~kg} / \mathrm{m}^{2}$ and a half (48.7\%) had HF and coronary artery (Table 1).

Patients in the highest ePVS tertiles had more frequently HF, higher N-terminal pro-B-type natriuretic peptide (NT-proBNP), LAV index, E/e' and lower RV isovolumic acceleration compared to patients in the lowest ePVS tertiles (all $\mathrm{p}<0.05$ ) (Table 1). In contrast, there was no significant difference in IVC, LVEDP and B-line counts across ePVS tertiles. 


\section{Clinical Determinants of Estimated Plasma Volume Status}

Univariable linear regression analysis showed that elderly age, female sex, lower BMI, diastolic BP, higher NTproBNP, larger LAV index and higher E/e’ were significantly associated with higher ePVS (Table 2). In multivariable linear regression models, only female sex, higher E/e' and lower diastolic BP were significantly associated with higher ePVS (Table 2).

Correlation between ePVS and congestion markers across heart rhythm and LVEF strata is shown in Supplementary table 1. ePVS significantly correlated with E/e' only in patients with sinus rhythm, whereas similar correlations between ePVS and congestion marker were found across LVEF strata.

\section{Interplay between Sex, Estimated Plasma Volume Status and other Congestion Markers}

ePVS was found to be significantly correlated with NT-proBNP (rho=0.36, $\mathrm{p}=0.01), \mathrm{E} / \mathrm{e}^{\prime}(\mathrm{rho}=0.33, \mathrm{p}<0.01$ ) and LAV index (rho=0.31, $\mathrm{p}<0.01$ ). Among congestion markers, only LVEDP was observed to have a sex-specific association with ePVS solely in females (rho $=0.53, \mathrm{p}<0.01$ in females and $\mathrm{rho}=-0.04, \mathrm{p}=0.76$ in males; $\mathrm{P}_{\text {interaction }}=0.08$ ) (Figure 1). Of note, LVEDP was not associated with higher ePVS in either univariable or multivariable analysis (Table 2).

\section{Estimated Plasma Volume Status Calculated by the Hakim formula}

Sex-specific ePVS tertiles derived from the Hakim formula were also applied in the present population [median $(\mathrm{IQR})=-9.45(-15.61-1.06) \%$ in males and $-7.29(-10.01-4.02) \%$ in females] (Supplementary table 2). Patients with the highest ePVS tertiles were older, had lower BMI and were less likely to have atrial fibrillation (all pvalue $<0.05$ ). However, there were no significant differences in biological, echocardiographic and invasive hemodynamic congestion markers across ePVS tertiles.

Multivariable linear regression models showed that ePVS was only associated with BMI and diastolic BP (Supplementary table 3).

\section{Discussion}

The current study is the first to assess the association of ePVS with clinical, biological, echocardiographic and invasive hemodynamic congestion markers. Our main findings are that: 1) higher ePVS derived from the Duarte formula was significantly associated with higher E/e' in multivariable analysis; 2) LVEDP was correlated with ePVS using the Duarte formula in females, while not associated with ePVS in the overall population; 3) ePVS derived from the Hakim formula was not associated with usual congestion markers. The above results suggest that ePVS derived 
from the Duarte formula may be an easily-accessible surrogate of measured markers of left-sided hemodynamic congestion in routine clinical practice.

\section{Estimated Plasma Volume Status - a left-sided congestion variable}

Our findings outline certain underlying features of plasma volume that have not been previously addressed. Among all patients included in our study, results showed that higher E/e' was associated with a higher ePVS level, but not with B-lines or LVEDP. There is growing evidence linking pulmonary interstitial edema quantified by lung ultrasound and elevated invasive measurements of LV filling pressures ${ }^{16,22}$. In contrast, a recent meta-analysis emphasized the lack of diagnostic value of E/e' ratio in predicting LV filling pressure ${ }^{23}$. This being said, E/e' is nevertheless a recognized congestion marker shown to be associated with clinical outcome in population-based or HF cohorts ${ }^{24-26}$. Given that we did not identify a significant association between ePVS and IVC, our findings further suggest that ePVS is more likely a left-sided congestion marker. This premise is also supported by the biological findings presented herein: patients within the highest ePVS tertiles had higher NT-proBNP, which is also typically considered as a left-sided congestion marker ${ }^{27,}{ }^{28}$. This result is also in keeping with previous reports in patients with HF and reduced or preserved $\operatorname{LVEF}^{3,4,29,30}$. In addition, we observed a better correlation between ePVS and E/e' in patients with sinus rhythm. It may be partly explained by the lack of predictive performance of Doppler echocardiography for LV pressures in patients with atrial fibrillation ${ }^{19}$.

The absence of a strong association between IVC and ePVS may be partly explained by the fact that over twothirds of the total blood volume resides in the venous circulation, which is relatively unaffected by changes in fluid volume given its high capacitance ${ }^{31}$. Another noteworthy finding of the present study is the strong association between lower diastolic BP and increased ePVS. BP is an important modulator of the complex interaction between interstitial fluid and plasma volume ${ }^{1}$. This could provide some pathophysiological basis for decreased diastolic BP favoring intravascular volume retention, which would translate into higher ePVS.

\section{Sex Difference in the association of Estimated Plasma Volume Status with other markers of congestion}

LVEDP was observed herein to be positively correlated with ePVS in females but not in males. Women have been shown to be more prone to impaired LV diastolic reserve ${ }^{14,32}$. This may partly explain why a higher left volume load (as measured by ePVS) was better correlated with LVEDP since the left ventricle in women (particularly in older women) is unable to mitigate intravascular pressure. The same amount of volume could indeed translate into different pressure levels according to the intrinsic diastolic properties of the heart. Irrespectively, these findings suggest that increased ePVS may be a more relevant marker of cardiopulmonary congestion in females ${ }^{33}{ }^{34}$. In contrast, there was 
no sex-dependent interaction of ePVS with other congestion markers such as NT-proBNP and E/e'. Both congestion markers were reported to have sex-dependency ${ }^{35-37}$, which may influence this sex-dependent interaction. The pathophysiological mechanism which may explain the sex-different association of ePVS with LVEDP needs to be further evaluated in future studies. Both clinical studies and animal studies would be interesting to refine our understanding of these differences in association between congestion variables.

\section{Clinical Perspectives}

Hemodynamic congestion can precede symptoms of congestion by several days. Plasma volume, estimated from hemoglobin/hematocrit using Duarte's formula or hematocrit/body weight using the Hakim formula, could represent easy-to-use markers in routine clinical practice. In contrast, we observed no significant association between congestion markers and ePVS derived from the Hakim formula. This differential association could be related to the Hakim formula incorporating "dry" body weight. There is a complex interplay of congestion and cachexia in HF patients which may explain that PV estimated from Hakim formula becomes less effective in this clinical setting ${ }^{38,} 39$. Importantly, previous reports showed moderate associations between ePVS derived from Duarte/Hakim formula and radiotracer-based quantitative plasma volume measurements which could explain variations of association between ePVS and other congestion markers. In contrast, Duarte-derived ePVS was significantly associated with E/e' (in the whole population) and LVEDP (in females) in the current study (Figure 2).

ePVS using Duarte's formula may be a useful integrative marker of left-sided hemodynamic congestion. Other congestion markers such as E/e' and LVEDP often cannot be repeatedly measured especially in the context of ambulatory patients with $\mathrm{HF}^{28}$. Therefore, PV estimated from Duarte formula could potentially become a useful congestion marker in the management of HF given its low cost and practicability. Large-scale multicenter studies are invariably needed to determine whether ePVS-guided treatment can improve clinical outcome in HF patients.

\section{Limitations}

First, this is a single-center cohort study; thus, there may be residual confounding and generalizability is not unequivocal. The moderate size of our cohort only yielded moderate statistical power. Second, we had no direct measurement of plasma volume by conventional radioisotope-labeled albumin or red blood cell assays, although these techniques are relatively impractical in routine clinical practice. The concordance between estimated and measured PV is still a matter of debate. Adequation for ePVS in the specific context of HF, especially in patients with large variations in body weight, should be further studied. In addition, Patients did not undergo catherization with a highfidelity micromanometer-tip catheter. Third, ambulatory patients were recruited in this study and consequently 
experienced less severe degrees of congestion than patients typically included in acute HF registries: Our results are thus only relevant for these lower risk patients.

Lastly, the sex-specific association identified herein could also be a chance finding. Further investigations are needed to determine whether a reproducible sex-specific pattern is observed for the association between ePVS and other congestion markers.

\section{Conclusion}

ePVS is associated with E/e' regardless of sex difference and is associated with invasively-measured LV filling pressure only in females. These results suggest that ePVS may be a marker of left-sided hemodynamic congestion rather than pulmonary interstitial edema or systemic congestion.

\section{References}

1. Miller WL. Fluid Volume Overload and Congestion in Heart Failure: Time to Reconsider Pathophysiology and How Volume Is Assessed. Circ Heart Fail. 2016;9:e002922.

2. Francis GS, Benedict C, Johnstone DE, Kirlin PC, Nicklas J, Liang CS, Kubo SH, Rudin-Toretsky E and Yusuf S. Comparison of neuroendocrine activation in patients with left ventricular dysfunction with and without congestive heart failure. A substudy of the Studies of Left Ventricular Dysfunction (SOLVD). Circulation. 1990;82:1724-9.

3. Duarte K, Monnez JM, Albuisson E, Pitt B, Zannad F and Rossignol P. Prognostic Value of Estimated Plasma Volume in Heart Failure. JACC Heart Fail. 2015;3:886-93.

4. Ling HZ, Flint J, Damgaard M, Bonfils PK, Cheng AS, Aggarwal S, Velmurugan S, Mendonca M, Rashid M, Kang S, Papalia F, Weissert S, Coats CJ, Thomas M, Kuskowski M, Cohn JN, Woldman S, Anand IS and Okonko DO. Calculated plasma volume status and prognosis in chronic heart failure. Eur J Heart Fail. 2015;17:35-43.

5. Kobayashi M, Rossignol P, Ferreira JP, Aragao I, Paku Y, Iwasaki Y, Watanabe M, Fudim M, Duarte K, Zannad F and Girerd N. Prognostic value of estimated plasma volume in acute heart failure in three cohort studies. Clin Res Cardiol. 2018. 6. Chouihed T, Rossignol P, Bassand A, Duarte K, Kobayashi M, Jaeger D, Sadoune S, Buessler A, Nace L, Giacomin G, Hutter T, Barbe F, Salignac S, Jay N, Zannad F and Girerd N. Diagnostic and prognostic value of plasma volume status at emergency department admission in dyspneic patients: results from the PARADISE cohort. Clin Res Cardiol. 2018.

7. $\quad$ Fudim M and Miller WL. Calculated Estimates of Plasma Volume in Patients With Chronic Heart Failure-Comparison With Measured Volumes. J Card Fail. 2018.

8. Martens P, Nijst P, Dupont M and Mullens W. The optimal plasma volume status in heart failure in relation to clinical outcome. J Card Fail. 2018.

9. Dekkers CCJ, Sjostrom CD, Greasley PJ, Cain V, Boulton DW and Heerspink HJL. Effects of the sodium-glucose cotransporter-2 inhibitor dapagliflozin on estimated plasma volume in patients with type 2 diabetes. Diabetes, obesity \& metabolism. 2019. 
MA, Butler J, Filippatos G and investigators ET. Haemoconcentration, renal function, and post-discharge outcomes among patients hospitalized for heart failure with reduced ejection fraction: insights from the EVEREST trial. Eur J Heart Fail. 2013;15:1401-11.

11. Testani JM, Chen J, McCauley BD, Kimmel SE and Shannon RP. Potential effects of aggressive decongestion during the treatment of decompensated heart failure on renal function and survival. Circulation. 2010;122:265-72.

12. van der Meer P, Postmus D, Ponikowski P, Cleland JG, O'Connor CM, Cotter G, Metra M, Davison BA, Givertz MM, Mansoor GA, Teerlink JR, Massie BM, Hillege HL and Voors AA. The predictive value of short-term changes in hemoglobin concentration in patients presenting with acute decompensated heart failure. J Am Coll Cardiol. 2013;61:1973-81.

13. Murphy WG. The sex difference in haemoglobin levels in adults - mechanisms, causes, and consequences. Blood reviews. 2014;28:41-7.

14. Beale AL, Nanayakkara S, Segan L, Mariani JA, Maeder MT, van Empel V, Vizi D, Evans S, Lam CSP and Kaye DM. Sex Differences in Heart Failure With Preserved Ejection Fraction Pathophysiology: A Detailed Invasive Hemodynamic and Echocardiographic Analysis. JACC Heart Fail. 2019;7:239-249.

15. Beale AL, Meyer P, Marwick TH, Lam CSP and Kaye DM. Sex Differences in Cardiovascular Pathophysiology: Why Women Are Overrepresented in Heart Failure With Preserved Ejection Fraction. Circulation. 2018;138:198-205.

16. Hubert A, Girerd N, Le Breton H, Galli E, Latar I, Fournet M, Mabo P, Schnell F, Leclercq C and Donal E. Diagnostic accuracy of lung ultrasound for identification of elevated left ventricular filling pressure. Int J Cardiol. 2019;281:62-68.

17. Ponikowski P, Voors AA, Anker SD, Bueno H, Cleland JG, Coats AJ, Falk V, Gonzalez-Juanatey JR, Harjola VP, Jankowska EA, Jessup M, Linde C, Nihoyannopoulos P, Parissis JT, Pieske B, Riley JP, Rosano GM, Ruilope LM, Ruschitzka F, Rutten FH, van der Meer P, Authors/Task Force M and Document R. 2016 ESC Guidelines for the diagnosis and treatment of acute and chronic heart failure: The Task Force for the diagnosis and treatment of acute and chronic heart failure of the European Society of Cardiology (ESC). Developed with the special contribution of the Heart Failure Association (HFA) of the ESC. Eur $J$ Heart Fail. 2016;18:891-975.

18. Levey AS, Stevens LA, Schmid CH, Zhang YL, Castro AF, 3rd, Feldman HI, Kusek JW, Eggers P, Van Lente F, Greene T and Coresh J. A new equation to estimate glomerular filtration rate. Ann Intern Med. 2009;150:604-12.

19. Nagueh SF, Smiseth OA, Appleton CP, Byrd BF, 3rd, Dokainish H, Edvardsen T, Flachskampf FA, Gillebert TC, Klein AL, Lancellotti P, Marino P, Oh JK, Popescu BA and Waggoner AD. Recommendations for the Evaluation of Left Ventricular Diastolic Function by Echocardiography: An Update from the American Society of Echocardiography and the European Association of Cardiovascular Imaging. J Am Soc Echocardiogr. 2016;29:277-314.

20. Picano E, Frassi F, Agricola E, Gligorova S, Gargani L and Mottola G. Ultrasound lung comets: a clinically useful sign of extravascular lung water. J Am Soc Echocardiogr. 2006;19:356-63.

21. RM. H. Plasmapheresis. In: I. D. JT, B. PG and I. TS, eds. Handbook of dialysis, 3rd ed Philadelphia: Lippincott Williams and Wilkins; 2001: 236.

22. Platz E, Lattanzi A, Agbo C, Takeuchi M, Resnic FS, Solomon SD and Desai AS. Utility of lung ultrasound in predicting pulmonary and cardiac pressures. European journal of heart failure. 2012;14:1276-84.

23. Sharifov OF, Schiros CG, Aban I, Denney TS and Gupta H. Diagnostic Accuracy of Tissue Doppler Index E/e' for Evaluating Left Ventricular Filling Pressure and Diastolic Dysfunction/Heart Failure With Preserved Ejection Fraction: A Systematic Review and Meta-Analysis. J Am Heart Assoc. 2016;5.

24. Nagueh SF. Left Ventricular Diastolic Function: Understanding Pathophysiology, Diagnosis, and Prognosis With Echocardiography. JACC CardiovasC Imaging. 2019.

25. Shah AM, Claggett B, Kitzman D, Biering-Sorensen T, Jensen JS, Cheng S, Matsushita K, Konety S, Folsom AR, Mosley TH, Wright JD, Heiss G and Solomon SD. Contemporary Assessment of Left Ventricular Diastolic Function in Older Adults: The Atherosclerosis Risk in Communities Study. Circulation. 2017;135:426-439. 
of B-type natriuretic peptide and tissue Doppler echocardiography in the prognosis of patients with congestive heart failure. $J$ Am Coll Cardiol. 2005;45:1223-6.

27. Neeland IJ, Drazner MH, Berry JD, Ayers CR, deFilippi C, Seliger SL, Nambi V, McGuire DK, Omland T and de Lemos JA. Biomarkers of chronic cardiac injury and hemodynamic stress identify a malignant phenotype of left ventricular hypertrophy in the general population. J Am Coll Cardiol. 2013;61:187-95.

28. Girerd N, Seronde MF, Coiro S, Chouihed T, Bilbault P, Braun F, Kenizou D, Maillier B, Nazeyrollas P, Roul G, Fillieux L, Abraham WT, Januzzi J, Jr., Sebbag L, Zannad F, Mebazaa A and Rossignol P. Integrative Assessment of Congestion in Heart Failure Throughout the Patient Journey. JACC Heart Fail. 2018;6:273-285.

29. Rossignol P, Menard J, Fay R, Gustafsson F, Pitt B and Zannad F. Eplerenone survival benefits in heart failure patients post-myocardial infarction are independent from its diuretic and potassium-sparing effects. Insights from an EPHESUS (Eplerenone Post-Acute Myocardial Infarction Heart Failure Efficacy and Survival Study) substudy. J Am Coll Cardiol. 2011;58:1958-66.

30. Grodin JL, Philips S, Mullens W, Nijst P, Martens P, Fang JC, Drazner MH, Tang WHW and Pandey A. Prognostic implications of plasma volume status estimates in heart failure with preserved ejection fraction: insights from TOPCAT. Eur $J$ Heart Fail. 2019.

31. Gelman S. Venous function and central venous pressure: a physiologic story. Anesthesiology. 2008;108:735-48.

32. Galderisi M, Anderson KM, Wilson PW and Levy D. Echocardiographic evidence for the existence of a distinct diabetic cardiomyopathy (the Framingham Heart Study). Am J Cardiol. 1991;68:85-9.

33. Redfield MM, Jacobsen SJ, Borlaug BA, Rodeheffer RJ and Kass DA. Age- and gender-related ventricular-vascular stiffening: a community-based study. Circulation. 2005;112:2254-62.

34. Najjar SS, Schulman SP, Gerstenblith G, Fleg JL, Kass DA, O'Connor F, Becker LC and Lakatta EG. Age and gender affect ventricular-vascular coupling during aerobic exercise. J Am Coll Cardiol. 2004;44:611-7.

35. Daniels LB and Maisel AS. Natriuretic peptides. J Am Coll Cardiol. 2007;50:2357-68.

36. Rueda-Ochoa OL, Smiderle-Gelain MA, Rizopoulos D, Dhana K, van den Berge JK, Echeverria LE, Ikram MA, Deckers JW, Franco $\mathrm{OH}$ and Kavousi M. Risk factors for longitudinal changes in left ventricular diastolic function among women and men. Heart. 2019.

37. Flint N, Kaufman N, Gal-Oz A, Margolis G, Topilsky Y, Keren G and Shacham Y. Echocardiographic correlates of left ventricular filling pressures and acute cardio-renal syndrome in ST segment elevation myocardial infarction patients. Clin Res Cardiol. 2017;106:120-126.

38. Ambrosy AP, Cerbin LP, Armstrong PW, Butler J, Coles A, DeVore AD, Dunlap ME, Ezekowitz JA, Felker GM, Fudim M, Greene SJ, Hernandez AF, O'Connor CM, Schulte P, Starling RC, Teerlink JR, Voors AA and Mentz RJ. Body Weight Change During and After Hospitalization for Acute Heart Failure: Patient Characteristics, Markers of Congestion, and Outcomes: Findings From the ASCEND-HF Trial. JACC Heart Fail. 2017;5:1-13.

39. Anker SD, Negassa A, Coats AJS, Afzal R, Poole-Wilson PA, Cohn JN and Yusuf S. Prognostic importance of weight loss in chronic heart failure and the effect of treatment with angiotensin-converting-enzyme inhibitors: an observational study. The Lancet. 2003;361:1077-1083. 
Table 1. Patient Characteristics according to Sex-specific Tertiles of Estimated Plasma Volume Status

* Sex-specific tertiles indicate the tertiles derived from males and females separately.

M, male; F, female; COPD, chronic obstructive pulmonary disease; ACEi, angiotensin converting enzyme inhibitor; ARB, angiotensin receptor blocker; MRA, mineralocorticoid receptor antagonist; NYHA, New York Heart Association; BP, blood pressure; eGFR, estimated glomerular filtration rate; NT proBNP, N-terminal prohormone brain natriuretic peptide; ePVS, estimated plasma volume status; LVSV, left ventricular systolic volume; LAV, left atrial volume; LVEF, left ventricular ejection fraction; E/A, ratio of peak early and late diastolic velocities; e', mean value of early diastolic velocity at the septal and lateral sites of the mitral annulus; E/e', ratio of early mitral inflow velocity and mitral annular early diastolic velocity; RAV, right atrial volume; TAPSE, tricuspid annular plane systolic excursion; IVA, isovolumic acceleration; IVC, inferior vena cava; PASP, pulmonary artery systolic pressure; LVEDP, left ventricular end-diastolic pressure.

Table 2. Multivariable Model for the Association of Clinical, Biological and Hemodynamic Parameters with Estimated Plasma Volume Status

NYHA, New York Heart Association; BP, diastolic blood pressure; eGFR, estimated glomerular filtration rate; NT proBNP, Nterminal prohormone brain natriuretic peptide; LVSV, left ventricular stroke volume; LAV, left atrial volume; E/A, ratio of peak early and late diastolic velocities; E/e', ratio of early mitral inflow velocity and mitral annular early diastolic velocity; RAV, right atrial volume; TAPSE, tricuspid annular plane systolic excursion; IVA, isovolumic acceleration; IVC, inferior vena cava; PASP, pulmonary artery systolic pressure; LVEDP, left ventricular end-diastolic pressure. 
Table 1. Patient Characteristics according to Sex-specific Tertiles of Estimated Plasma Volume Status

\begin{tabular}{|c|c|c|c|c|c|c|c|}
\hline & Global & Low & Intermediate & High & & & \\
\hline & $(\mathrm{N}=78)$ & $\begin{array}{c}\mathrm{M},<3.8 \mathrm{ml} / \mathrm{g} ; \\
\mathrm{F},<4.4 \mathrm{ml} / \mathrm{g} \\
(\mathrm{N}=26)\end{array}$ & $\begin{array}{c}\mathrm{M}, 3.8-4.5 \mathrm{ml} / \mathrm{g} \\
\mathrm{F}, 4.4-5.0 \mathrm{ml} / \mathrm{g} \\
(\mathrm{N}=26)\end{array}$ & $\begin{array}{c}\mathrm{M},>4.5 \mathrm{ml} / \mathrm{g} \\
\mathrm{F},>5.0 \mathrm{ml} / \mathrm{g} \\
(\mathrm{N}=26)\end{array}$ & $\begin{array}{c}\text { p- } \\
\text { value }\end{array}$ & $\begin{array}{l}\text { p-Value } \\
1 \text { vs. } 3\end{array}$ & $\begin{array}{l}\text { p-Value } \\
2 \text { vs. } 3\end{array}$ \\
\hline Age, yrs & $\begin{array}{c}74.5 \\
(67.0-80.0)\end{array}$ & $\begin{array}{c}73.5 \\
(64.0-78.0)\end{array}$ & $\begin{array}{c}71.5 \\
(67.0-78.0)\end{array}$ & $\begin{array}{c}77.5 \\
(70.0-82.0)\end{array}$ & 0.15 & 0.11 & 0.08 \\
\hline Males, N (\%) & $54(69.2 \%)$ & $18(69.2 \%)$ & $18(69.2 \%)$ & $18(69.2 \%)$ & NA & NA & NA \\
\hline Body mass index, $\mathrm{kg} / \mathrm{m}^{2}$ & $\begin{array}{c}25.7 \\
(22.9-29.5)\end{array}$ & $\begin{array}{c}27.9 \\
(24.7-32.6)\end{array}$ & $\begin{array}{c}25.9 \\
(23.3-28.9)\end{array}$ & $\begin{array}{c}23.6 \\
(20.7-26.7)\end{array}$ & $<\mathbf{0 . 0 1}$ & $<\mathbf{0 . 0 1}$ & 0.12 \\
\hline \multicolumn{8}{|l|}{ Medical history, N (\%) } \\
\hline Hypertension & $53(67.9 \%)$ & $16(61.5 \%)$ & $18(69.2 \%)$ & $19(73.1 \%)$ & 0.66 & 0.38 & 0.76 \\
\hline Dyslipidemia & 35 (44.9\%) & $12(46.2 \%)$ & $10(38.5 \%)$ & $13(50.0 \%)$ & 0.70 & 0.78 & 0.4 \\
\hline Diabetes mellitus & $16(20.5 \%)$ & $2(7.7 \%)$ & 7 (26.9 \%) & 7 (26.9 \%) & 0.14 & 0.08 & 0.99 \\
\hline Coronary artery disease & $38(48.7 \%)$ & $9(34.6 \%)$ & $12(46.2 \%)$ & $17(65.4 \%)$ & 0.08 & 0.03 & 0.17 \\
\hline Heart failure & $38(48.7 \%)$ & $8(30.8 \%)$ & $13(50.0 \%)$ & $17(65.4 \%)$ & 0.04 & 0.01 & 0.26 \\
\hline Atrial fibrillation & $23(29.5 \%)$ & $10(38.5 \%)$ & $7(26.9 \%)$ & $6(23.1 \%)$ & 0.45 & 0.23 & 0.75 \\
\hline COPD & $6(7.7 \%)$ & $2(7.7 \%)$ & $4(15.4 \%)$ & $0(0 \%)$ & 0.11 & 0.99 & 0.99 \\
\hline Smoking & $30(38.5 \%)$ & $10(38.5 \%)$ & $12(46.2 \%)$ & $8(30.8 \%)$ & 0.52 & 0.56 & 0.26 \\
\hline \multicolumn{8}{|l|}{ Medications, N (\%) } \\
\hline ACEi/ARB & $48(61.5 \%)$ & $15(57.7 \%)$ & $16(61.5 \%)$ & $17(65.4 \%)$ & 0.85 & 0.57 & 0.77 \\
\hline Calcium channel blocker & $4(5.1 \%)$ & $1(3.8 \%)$ & $1(3.8 \%)$ & $2(7.7 \%)$ & 0.77 & 0.56 & 0.56 \\
\hline Beta-blocker & $44(56.4 \%)$ & $17(65.4 \%)$ & $13(50.0 \%)$ & $14(53.8 \%)$ & 0.51 & 0.40 & 0.78 \\
\hline MRA & $8(10.3 \%)$ & $2(7.7 \%)$ & $2(7.7 \%)$ & $4(15.4 \%)$ & 0.57 & 0.39 & 0.39 \\
\hline \multicolumn{8}{|l|}{ Clinical profile } \\
\hline NYHA III+IV, N (\%) & $21(26.9 \%)$ & $6(23.1 \%)$ & 8 (30.8 \%) & 7 (26.9 \%) & 0.82 & 0.75 & 0.76 \\
\hline Systolic BP, mmHg & $\begin{array}{c}134.0 \\
(118.0-148.0)\end{array}$ & $\begin{array}{c}139.0 \\
(130.0-144.0)\end{array}$ & $\begin{array}{c}133.0 \\
(119.0-148.0)\end{array}$ & $\begin{array}{c}130.0 \\
(110.0-147.0)\end{array}$ & 0.48 & 0.27 & 0.64 \\
\hline Diastolic BP, mmHg & $\begin{array}{c}72.5 \\
(65.0-84.0)\end{array}$ & $\begin{array}{c}76.0 \\
(68.0-90.0)\end{array}$ & $\begin{array}{c}75.0 \\
(67.0-81.0)\end{array}$ & $\begin{array}{c}67.0 \\
(65.0-80.0)\end{array}$ & 0.17 & 0.06 & 0.20 \\
\hline Heart rate, bpm & $\begin{array}{c}70.5 \\
(61.0-83.0)\end{array}$ & $\begin{array}{c}70.0 \\
(61.0-86.0)\end{array}$ & $\begin{array}{c}76.5 \\
(59.0-83.0)\end{array}$ & $\begin{array}{c}67.0 \\
(62.0-75.0)\end{array}$ & 0.69 & 0.82 & 0.35 \\
\hline \multicolumn{8}{|l|}{ Laboratory measurements } \\
\hline Hemoglobin, g/dl & $\begin{array}{c}13.6 \\
(12.5-14.7)\end{array}$ & $\begin{array}{c}15.0 \\
(14.3-15.4)\end{array}$ & $\begin{array}{c}13.9 \\
(13.3-14.3)\end{array}$ & $\begin{array}{c}11.9 \\
(10.9-12.5)\end{array}$ & $<0.01$ & $<0.01$ & $<0.01$ \\
\hline Sodium, mmol/l & $\begin{array}{c}140.0 \\
(137.0-141.0)\end{array}$ & $\begin{array}{c}140.0 \\
(138.0-141.0)\end{array}$ & $\begin{array}{c}140.0 \\
(138.0-142.0)\end{array}$ & $\begin{array}{c}138.0 \\
(137.0-141.0)\end{array}$ & 0.22 & 0.18 & 0.12 \\
\hline eGFR, $\mathrm{ml} / \mathrm{min} / 1.73 \mathrm{~m}^{2}$ & $\begin{array}{c}70.0 \\
(53.0-85.0)\end{array}$ & $\begin{array}{c}67.1 \\
(57.2-88.0)\end{array}$ & $\begin{array}{c}75.3 \\
(48.0-85.0)\end{array}$ & $\begin{array}{c}71.0 \\
(49.0-81.0)\end{array}$ & 0.66 & 0.44 & 0.53 \\
\hline NT proBNP, pg/ml & $\begin{array}{c}1025 \\
(283-2384)\end{array}$ & $\begin{array}{c}668 \\
(112-2168)\end{array}$ & $\begin{array}{c}576 \\
(172-1472)\end{array}$ & $\begin{array}{c}2327 \\
(1025-5752)\end{array}$ & 0.03 & 0.04 & 0.01 \\
\hline ePVS, ml/g & $\begin{array}{c}4.4 \\
(3.8-5.0)\end{array}$ & $\begin{array}{c}3.7 \\
(3.5-3.8)\end{array}$ & $\begin{array}{c}4.2 \\
(4.0-4.5)\end{array}$ & $\begin{array}{c}5.4 \\
(5.0-6.1)\end{array}$ & $<0.01$ & $<0.01$ & $<0.01$ \\
\hline \multicolumn{8}{|l|}{ LV function } \\
\hline LVSV index, $\mathrm{ml} / \mathrm{m}^{2}$ & $\begin{array}{c}31.4 \\
(19.3-50.6)\end{array}$ & $\begin{array}{c}29.6 \\
(18.3-42.7)\end{array}$ & $\begin{array}{c}34.8 \\
(23.2-59.1)\end{array}$ & $\begin{array}{c}42.7 \\
(20.9-69.2)\end{array}$ & 0.18 & 0.08 & 0.99 \\
\hline LAV index, $\mathbf{m l} / \mathbf{m}^{2}$ & $\begin{array}{c}47.7 \\
(33.4-62.3)\end{array}$ & $\begin{array}{c}47.3 \\
(31.8-58.9)\end{array}$ & $\begin{array}{c}41.9 \\
(33.3-52.3)\end{array}$ & $\begin{array}{c}55.4 \\
(44.4-65.5)\end{array}$ & 0.046 & 0.06 & 0.02 \\
\hline LVEF, \% & $\begin{array}{c}52.0 \\
(33.0-62.0)\end{array}$ & $\begin{array}{c}54.0 \\
(43.0-63.0)\end{array}$ & $\begin{array}{c}50.5 \\
(31.0-58.0)\end{array}$ & $\begin{array}{c}50.4 \\
(31.0-62.0)\end{array}$ & 0.25 & 0.25 & 0.76 \\
\hline LVEF $<40 \%$, N (\%) & $26(33.3 \%)$ & $4(15.4 \%)$ & $10(38.5 \%)$ & $12(46.2 \%)$ & 0.049 & 0.02 & 0.58 \\
\hline LVEF $\geq 50 \%, \quad N(\%)$ & 42 (53.8 \%) & 16 (61.5 \%) & $13(50.0 \%)$ & $13(50.0 \%)$ & 0.63 & 0.40 & 1.00 \\
\hline Global longitudinal strain, \% & $\begin{array}{c}-12.9 \\
(-18.4--8.6)\end{array}$ & $\begin{array}{c}-15.2 \\
(-19.0--10.0)\end{array}$ & $\begin{array}{c}-13.2 \\
(-19.4--8.6)\end{array}$ & $\begin{array}{c}-10.2 \\
(-16.9--7.4)\end{array}$ & 0.24 & 0.08 & 0.40 \\
\hline $\mathrm{E} / \mathrm{A}$ ratio $(\mathrm{N}=61)$ & $\begin{array}{c}0.9 \\
(0.7-1.6)\end{array}$ & $\begin{array}{c}0.9 \\
(0.6-1.6)\end{array}$ & $\begin{array}{c}0.9 \\
(0.7-1.5)\end{array}$ & $\begin{array}{c}1.1 \\
(0.7-1.8)\end{array}$ & 0.58 & 0.49 & 0.90 \\
\hline$e^{\prime}$ mean, $\mathrm{cm} / \mathrm{s}$ & $\begin{array}{c}6.5 \\
(4.5-8.5)\end{array}$ & $\begin{array}{c}6.8 \\
(5.5-10.0)\end{array}$ & $\begin{array}{c}6.5 \\
(5.0-9.0)\end{array}$ & $\begin{array}{c}6.0 \\
(3.5-7.0)\end{array}$ & 0.11 & 0.04 & 0.14 \\
\hline E/e' mean & $\begin{array}{c}12.5 \\
(9.3-18.3)\end{array}$ & $\begin{array}{c}10.9 \\
(8.5-15.0)\end{array}$ & $\begin{array}{c}11.7 \\
(8.6-15.6)\end{array}$ & $\begin{array}{c}16.3 \\
(11.6-22.6)\end{array}$ & 0.02 & 0.01 & 0.03 \\
\hline \multicolumn{8}{|l|}{ RV function } \\
\hline RAV index, $\mathbf{m l} / \mathbf{m}^{2}$ & $\begin{array}{c}25.4 \\
(19.5-34.4)\end{array}$ & $\begin{array}{c}29.4 \\
(19.4-44.8)\end{array}$ & $\begin{array}{c}22.8 \\
(19.5-28.8)\end{array}$ & $\begin{array}{c}26.3 \\
(19.5-34.4)\end{array}$ & 0.27 & 0.29 & 0.52 \\
\hline TAPSE, mm & $\begin{array}{c}22.8 \\
(18.0-25.3)\end{array}$ & $\begin{array}{c}23.0 \\
(19.0-26.0)\end{array}$ & $\begin{array}{c}24.0 \\
(20.0-30.0)\end{array}$ & $\begin{array}{c}20.5 \\
(18.0-24.0)\end{array}$ & 0.12 & 0.16 & 0.047 \\
\hline RV IVA, m/sec & $\begin{array}{c}1.4 \\
(0.9-2.1)\end{array}$ & $\begin{array}{c}1.3 \\
(0.9-1.6)\end{array}$ & $\begin{array}{c}1.9 \\
(1.4-2.3)\end{array}$ & $\begin{array}{c}1.1 \\
(0.8-1.9)\end{array}$ & 0.03 & 0.71 & 0.03 \\
\hline IVC dimension, mm & $\begin{array}{c}13.0 \\
(8.0-16.7)\end{array}$ & $\begin{array}{c}13.0 \\
(6.0-16.0)\end{array}$ & $\begin{array}{c}12.0 \\
(7.5-16.0)\end{array}$ & $\begin{array}{c}13.5 \\
(10.0-20.5)\end{array}$ & 0.29 & 0.20 & 0.15 \\
\hline estimated PAPS, mmHg & $\begin{array}{c}34.0 \\
(26.0-45.0)\end{array}$ & $\begin{array}{c}34.0 \\
(26.0-38.0)\end{array}$ & $\begin{array}{c}30.0 \\
(25.0-42.0)\end{array}$ & $\begin{array}{c}35.0 \\
(26.0-50.0)\end{array}$ & 0.38 & 0.21 & 0.28 \\
\hline
\end{tabular}

Other parameters 
LVEDP, mmHg

LV-PreA, mmHg $(\mathrm{N}=61)$

Total B-Lines
$16.0 \quad 15.5$

$\begin{array}{cc}(12.0-22.0) & (11.0-20.0) \\ 10.0 & 10.0\end{array}$

10.0

$(7.0-16.0)$

3.0

$(0.0-12.0)$
16.0

$(5.0-12.0)$

2.5

$(0.0-12.0)$
$(13.0$ - 21.0)

10.0

(6.5 - 16.0)

1.0
$(0.0-9.0)$
17.0

$(12.0-23.0)$

12.0

$(8.0$ - 16.0)

4.0
$(0.0-19.0)$

$\begin{array}{lll}0.77 & 0.52 & 0.79 \\ 0.33 & 0.15 & 0.54 \\ 0.52 & 0.46 & 0.29\end{array}$


Table 2. Multivariable Model for the Association of Clinical, Biological and Hemodynamic Parameters with Estimated Plasma Volume Status

\begin{tabular}{|c|c|c|c|c|}
\hline \multirow[b]{2}{*}{ Variables } & \multicolumn{2}{|c|}{ Univariable model } & \multicolumn{2}{|c|}{ Multivariable model } \\
\hline & $\beta(95 \% \mathrm{CI})$ & p-Value & $\beta(95 \% \mathrm{CI})$ & p-Value \\
\hline \multicolumn{5}{|l|}{ Clinical parameters } \\
\hline Age, yrs (per 5 yrs) & $0.15(0.04-0.26)$ & 0.01 & - & - \\
\hline Male sex & $-0.54(-0.99--0.08)$ & 0.02 & $-0.67(-1.25-0.08)$ & 0.03 \\
\hline Body mass index, $\mathrm{kg} / \mathrm{m}^{2}$ (per 5 kg/m²) & $-0.20(-0.39--0.01)$ & 0.04 & - & - \\
\hline Hypertension & $0.16(-0.31-0.62)$ & 0.50 & & \\
\hline Diabetes mellitus & $0.44(-0.09-0.97)$ & 0.09 & - & - \\
\hline Coronary artery disease & $0.27(-0.16-0.70)$ & 0.21 & & \\
\hline Heart failure & $0.52(0.10-0.94)$ & 0.02 & - & - \\
\hline NYHA III+IV & $0.41(-0.07-0.89)$ & 0.09 & - & - \\
\hline Diastolic BP, mmHg (per 5 mmHg) & $-0.13(-0.21--0.05)$ & $<0.001$ & $-0.22(-0.41--0.02)$ & 0.03 \\
\hline \multicolumn{5}{|l|}{ Biological parameters } \\
\hline Sodium, mmol/l (per 5 mmol/l) & $-0.14(-0.44-0.16)$ & 0.35 & & \\
\hline eGFR, $\mathrm{ml} / \mathrm{min} / 1.73 \mathrm{~m}^{2}\left(\right.$ per $\left.5 \mathrm{ml} / \mathrm{min} / 1.73 \mathrm{~m}^{2}\right)$ & $-0.03(-0.08-0.03)$ & 0.34 & & \\
\hline Log NT proBNP & $0.24(0.04-0.43)$ & 0.02 & & - \\
\hline \multicolumn{5}{|l|}{ Left ventricular function } \\
\hline LVSV index, $\mathrm{ml} / \mathrm{m}^{2}$ (per $\left.5 \mathrm{ml} / \mathrm{m}^{2}\right)$ & $0.02(-0.02-0.05)$ & 0.43 & & \\
\hline LAV index, $\mathrm{ml} / \mathrm{m}^{2}\left(\right.$ per $\left.5 \mathrm{ml} / \mathrm{m}^{2}\right)$ & $0.05(0.01-0.10)$ & 0.03 & - & - \\
\hline LV ejection fraction, \% (per 5\%) & $-0.02(-0.09-0.04)$ & 0.46 & & \\
\hline LV ejection fraction $<40 \%$ & $0.42(-0.03-0.87)$ & 0.07 & - & - \\
\hline Global longitudinal strain, \% & $0.02(-0.02-0.06)$ & 0.24 & & \\
\hline E/A ratio & $0.02(-0.25-0.28)$ & 0.91 & & \\
\hline E/e' mean & $0.04(0.01-0.06)$ & $<0.001$ & $0.03(0.01-0.06)$ & 0.03 \\
\hline \multicolumn{5}{|l|}{ Right ventricular function } \\
\hline TAPSE, mm & $-0.02(-0.06-0.02)$ & 0.27 & & \\
\hline RV IVA, m/sec & $-0.09(-0.29-0.12)$ & 0.40 & & \\
\hline IVC dimension, mm & $0.01(-0.03-0.05)$ & 0.51 & & \\
\hline estimated PAPS, mmHg (per 5 mmHg) & $0.06(-0.02-0.13)$ & 0.15 & & \\
\hline \multicolumn{5}{|l|}{ Other parameters } \\
\hline LVEDP, mmHg & $0.01(-0.02-0.04)$ & 0.37 & & \\
\hline Total B-Lines & $0.02(-0.01-0.04)$ & 0.18 & & \\
\hline
\end{tabular}


Figure 1. Scatterplots of Congestion Markers with Estimated Plasma Volume Status according to Sex Difference

ePVS, estimated plasma volume status; NT proBNP, N-terminal prohormone brain natriuretic peptide; E/e’, ratio of early mitral inflow velocity and mitral annular early diastolic velocity; LAV, left atrial volume; IVC, inferior vena cava; LVEDP, left ventricular end-diastolic pressure

Central Illustration. Association between Congestion Markers and Estimated Plasma Volume Status 


\section{Graphic abstract}

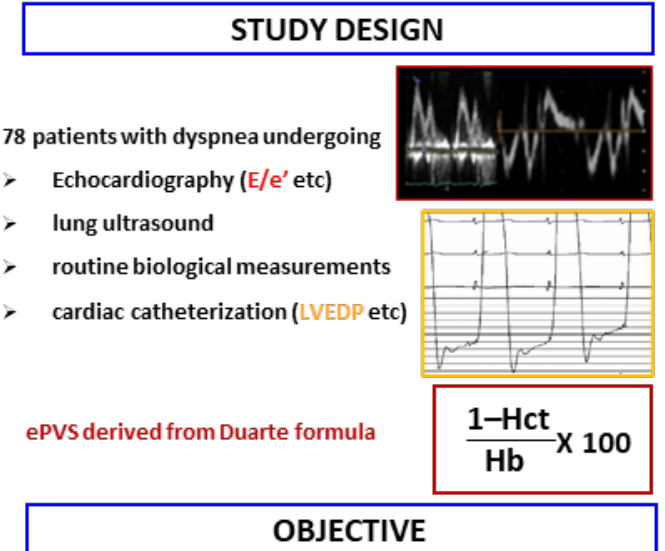

1) To study the association of ePVS with clinical, biological, echo graphic and invasive hemodynamic congestion variables

2) To investigate whether these associations are sex-dependent

\begin{tabular}{|c|c|c|c|}
\hline \multicolumn{4}{|c|}{ RESULTS } \\
\hline & \multicolumn{3}{|c|}{ Multivariable association with ePVS } \\
\hline \multirow{4}{*}{$E / e^{\prime}$} & & $\beta$ & $95 \% \mathrm{Cl}$ \\
\hline & Male & -0.67 & $-1.25-0.08$ \\
\hline & DBP & -0.22 & $-0.41--0.02$ \\
\hline & $E / e^{\prime}$ & 0.03 & $0.01-0.06$ \\
\hline
\end{tabular}

Sex-dependent association with ePVS

\section{LVEDP}

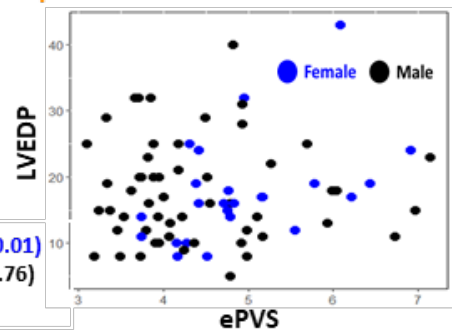


Figure 1. Scatterplots of Congestion Markers with Estimated Plasma Volume Status according to Sex Difference

Female Male
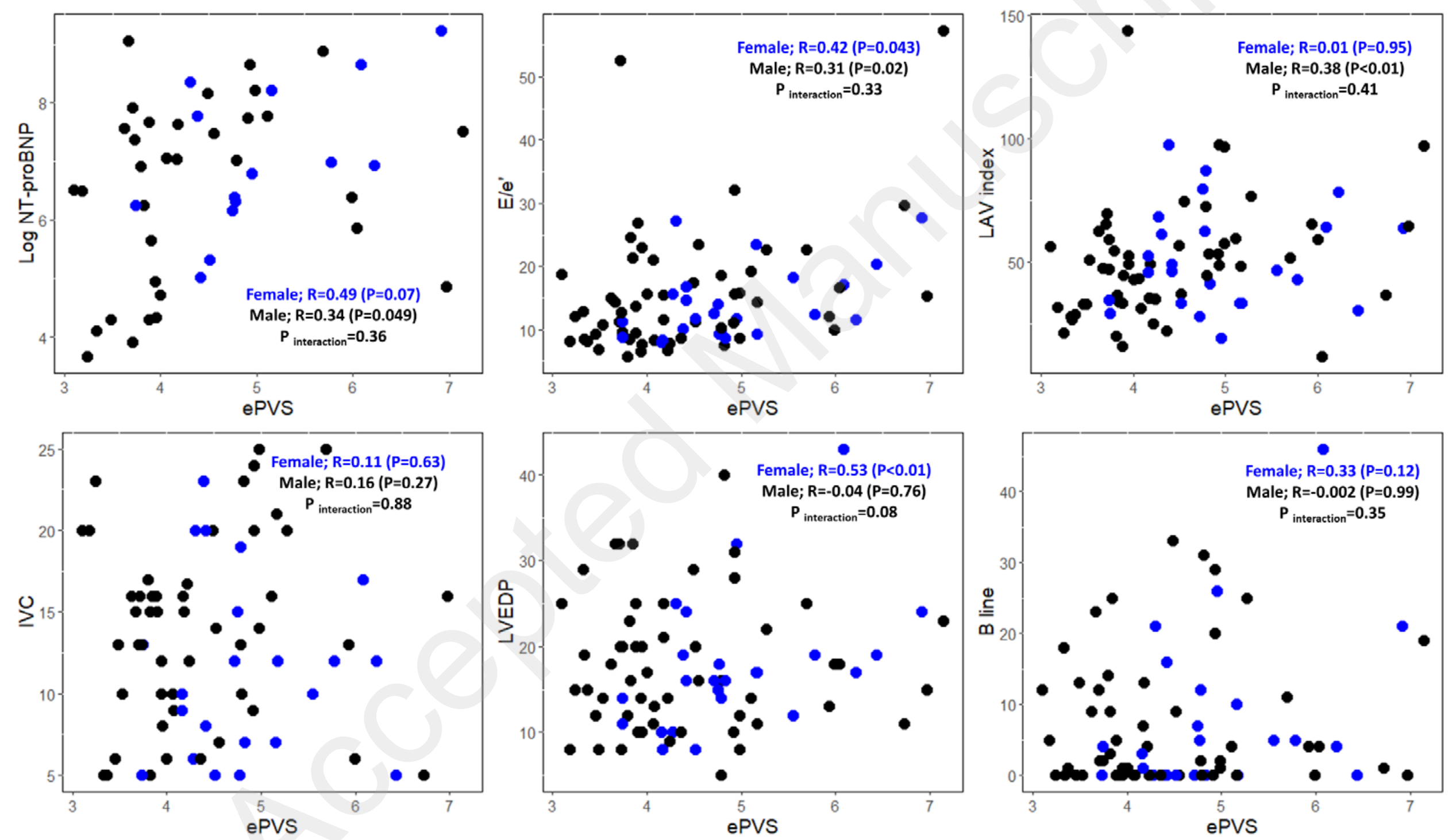


\section{Estimated Plasma Volume Status}

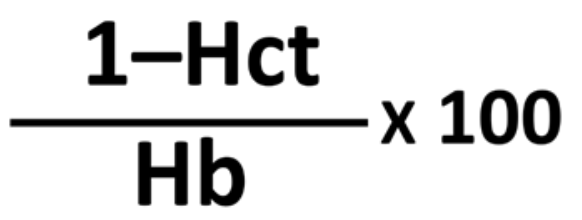

Independent association

\section{$E / e^{\prime}$}

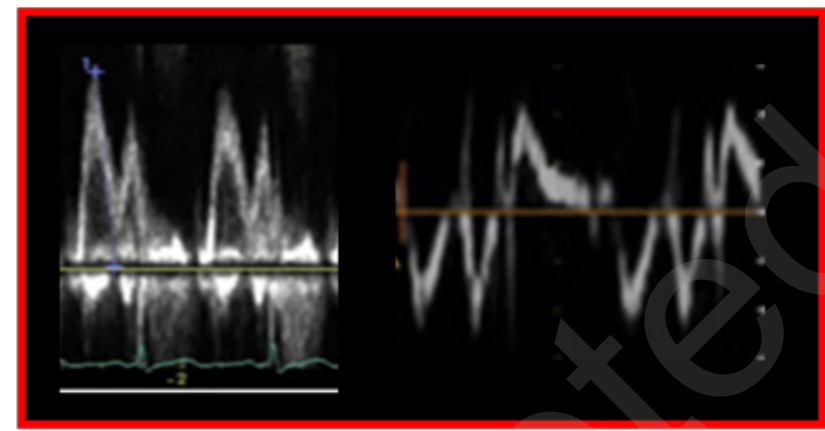

Multivariable association with ePVS in linear regression

\begin{tabular}{|l|c|c|}
\hline & $\boldsymbol{\beta}$ & $\mathbf{9 5 \%}$ Cl \\
\hline Male & -0.67 & $-1.25-0.08$ \\
\hline DBP & -0.22 & $-0.41--0.02$ \\
\hline E/e' & $\mathbf{0 . 0 3}$ & $\mathbf{0 . 0 1 - 0 . 0 6}$ \\
\hline
\end{tabular}

Sex-dependent association
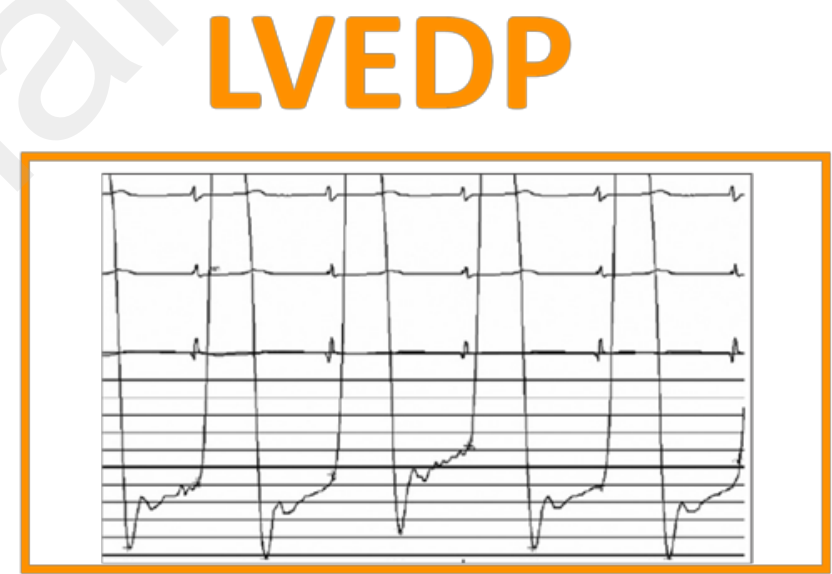

Female Male

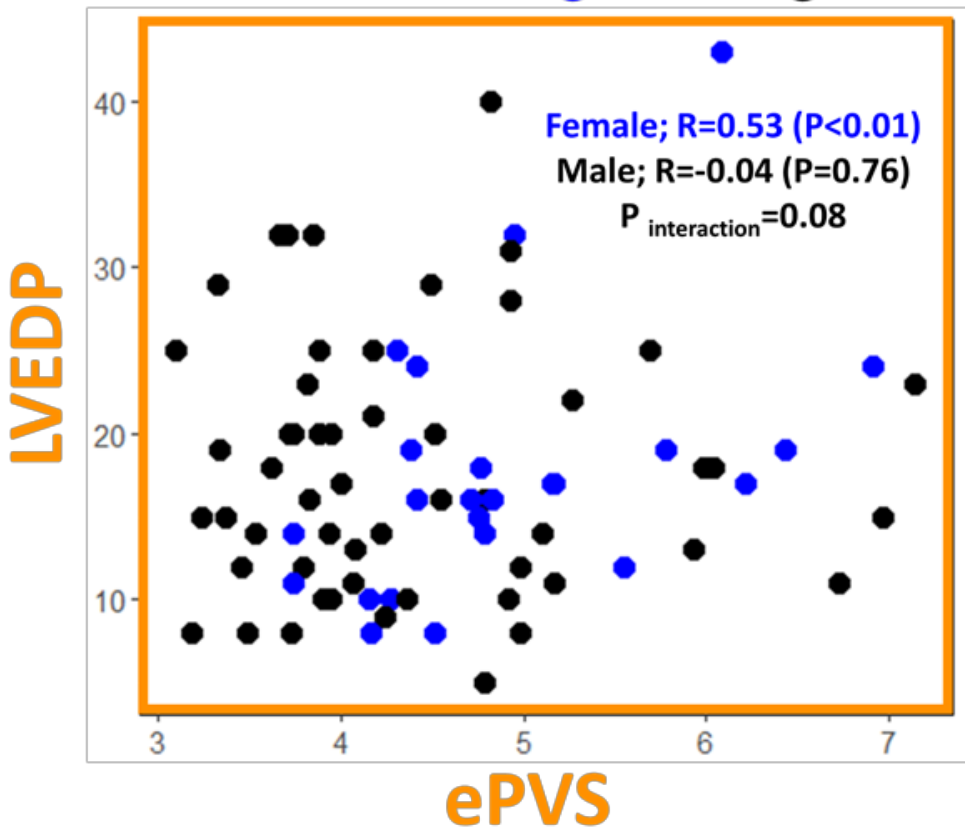


Supplementary table 1. Correlation Matrix between Estimated Plasma Volume Status and Congestion Markers across Heart Rhythm and Left Ventricular Ejection Fraction Strata

\begin{tabular}{|c|c|c|c|c|c|c|c|c|c|c|}
\hline & \multicolumn{2}{|c|}{$\begin{array}{l}\text { Sinus rhythm } \\
(\mathbf{N}=61)\end{array}$} & \multicolumn{2}{|c|}{$\begin{array}{l}\text { Atrial fibrillation } \\
(\mathrm{N}=17)\end{array}$} & \multirow{2}{*}{$\begin{array}{l}\text { p-value for } \\
\text { interaction }\end{array}$} & \multicolumn{2}{|c|}{$\begin{array}{c}\text { LVEF } \geq 50 \% \\
(\mathrm{~N}=42)\end{array}$} & \multicolumn{2}{|c|}{$\begin{array}{c}\text { LVEF }<50 \% \\
(\mathrm{~N}=36)\end{array}$} & \multirow{2}{*}{$\begin{array}{l}\text { p-value for } \\
\text { interaction }\end{array}$} \\
\hline & rho & p-value & rho & p-value & & rho & p-value & rho & p-value & \\
\hline Log NTproBNP & 0.49 & 0.002 & 0.26 & 0.43 & 0.93 & 0.47 & 0.01 & 0.44 & 0.06 & 0.57 \\
\hline E/e' mean & 0.39 & 0.002 & 0.06 & 0.82 & 0.02 & 0.33 & 0.03 & 0.31 & 0.06 & 0.30 \\
\hline LAV index & 0.31 & 0.01 & 0.36 & 0.16 & 0.84 & 0.25 & 0.11 & 0.34 & 0.04 & 0.34 \\
\hline IVC dimension & 0.11 & 0.41 & 0.19 & 0.48 & 0.60 & -0.06 & 0.72 & 0.25 & 0.14 & 0.84 \\
\hline LVEDP & 0.08 & 0.56 & 0.14 & 0.60 & 0.91 & 0.14 & 0.38 & 0.04 & 0.81 & 0.73 \\
\hline Total B-lines & 0.13 & 0.30 & -0.13 & 0.62 & 0.60 & 0.07 & 0.67 & 0.12 & 0.49 & 0.86 \\
\hline
\end{tabular}

Correlations were analyzed using Spearman's correlation.

NT proBNP, N-terminal prohormone brain natriuretic peptide; E/e’, ratio of early mitral inflow velocity and mitral annular early diastolic velocity; LAV, left atrial volume; IVC, inferior vena cava; LVEDP, left ventricular end-diastolic pressure. 
Supplementary table 2. Patient Characteristics according to Sex-specific Tertiles of Estimated Plasma Volume Status (Hakim formula)

\begin{tabular}{|c|c|c|c|c|c|}
\hline & \multicolumn{5}{|c|}{ Sex specific ePVS tertiles } \\
\hline & Global & Low & Intermediate & High & \\
\hline & $(\mathrm{N}=78)$ & $\begin{array}{c}M,<-12.9 \% \\
F,<-9.7 \% \\
(N=26) \\
\end{array}$ & $\begin{array}{c}\text { M, -12.9 - -3.4\% } \\
\text { F, }-9.7-0.2 \% \\
(N=26)\end{array}$ & $\begin{array}{c}M,-3.4 \%>\text {; } \\
F, 0.2 \%> \\
(N=26)\end{array}$ & p-value \\
\hline Age, yrs & $\begin{array}{c}74.5 \\
(67.0-80.0)\end{array}$ & $\begin{array}{c}71.5 \\
(64.0-76.0)\end{array}$ & $\begin{array}{c}75.0 \\
(67.0-79.0)\end{array}$ & $\begin{array}{c}78.0 \\
(70.0-83.0)\end{array}$ & 0.02 \\
\hline Males, N (\%) & $54(69.2 \%)$ & $18(69.2 \%)$ & $18(69.2 \%)$ & $18(69.2 \%)$ & NA \\
\hline Body mass index, $\mathrm{kg} / \mathrm{m}^{2}$ & $\begin{array}{c}25.7 \\
(22.9-29.5)\end{array}$ & $\begin{array}{c}29.8 \\
(25.9-32.7)\end{array}$ & $\begin{array}{c}25.3 \\
(22.9-28.7)\end{array}$ & $\begin{array}{c}23.1 \\
(20.7-25.2)\end{array}$ & $<0.001$ \\
\hline \multicolumn{6}{|l|}{ Medical history, N (\%) } \\
\hline Hypertension & $53(67.9 \%)$ & $18(69.2 \%)$ & $17(65.4 \%)$ & $18(69.2 \%)$ & 0.94 \\
\hline Dyslipidemia & 35 (44.9 \%) & 10 (38.5 \%) & 13 (50.0 \%) & 12 (46.2 \%) & 0.70 \\
\hline Diabetes mellitus & $16(20.5 \%)$ & $2(7.7 \%)$ & $9(34.6 \%)$ & $5(19.2 \%)$ & 0.06 \\
\hline Coronary artery disease & $38(48.7 \%)$ & $8(30.8 \%)$ & $14(53.8 \%)$ & $16(61.5 \%)$ & 0.07 \\
\hline Heart failure & $38(48.7 \%)$ & $11(42.3 \%)$ & $11(42.3 \%)$ & $16(61.5 \%)$ & 0.28 \\
\hline Atrial fibrillation & $23(29.5 \%)$ & $12(46.2 \%)$ & $4(15.4 \%)$ & 7 (26.9 \%) & 0.048 \\
\hline COPD & $6(7.7 \%)$ & $3(11.5 \%)$ & $3(11.5 \%)$ & $0(0 \%)$ & 0.20 \\
\hline Smoking & $30(38.5 \%)$ & $9(34.6 \%)$ & $12(46.2 \%)$ & $9(34.6 \%)$ & 0.61 \\
\hline \multicolumn{6}{|l|}{ Medications, N (\%) } \\
\hline ACEi/ARB & $48(61.5 \%)$ & $15(57.7 \%)$ & $17(65.4 \%)$ & $16(61.5 \%)$ & 0.85 \\
\hline Calcium channel blockers & $4(5.1 \%)$ & $1(3.8 \%)$ & $1(3.8 \%)$ & $2(7.7 \%)$ & 0.77 \\
\hline Beta-blocker & $44(56.4 \%)$ & $17(65.4 \%)$ & $11(42.3 \%)$ & $16(61.5 \%)$ & 0.20 \\
\hline MRA & $8(10.3 \%)$ & $2(7.7 \%)$ & $4(15.4 \%)$ & $2(7.7 \%)$ & 0.57 \\
\hline \multicolumn{6}{|l|}{ Clinical profile } \\
\hline NYHA III+IV, N (\%) & $21(26.9 \%)$ & 7 (26.9 \%) & $8(30.8 \%)$ & $6(23.1 \%)$ & 0.82 \\
\hline Systolic BP, mmHg & $\begin{array}{c}134.0 \\
(118.0-148.0)\end{array}$ & $\begin{array}{c}138.0 \\
(130.0-145.0)\end{array}$ & $\begin{array}{c}133.0 \\
(119.0-153.0)\end{array}$ & $\begin{array}{c}132.0 \\
(110.0-147.0)\end{array}$ & 0.55 \\
\hline Diastolic BP, mmHg & $\begin{array}{c}72.5 \\
(65.0-84.0)\end{array}$ & $\begin{array}{c}76.0 \\
(65.0-90.0)\end{array}$ & $\begin{array}{c}75.0 \\
(67.0-80.0)\end{array}$ & $\begin{array}{c}70.0 \\
(65.0-80.0)\end{array}$ & 0.24 \\
\hline Heart rate, bpm & $\begin{array}{c}70.5 \\
(61.0-83.0)\end{array}$ & $\begin{array}{c}75.0 \\
(64.0-90.0)\end{array}$ & $\begin{array}{c}72.5 \\
(60.0-83.0)\end{array}$ & $\begin{array}{c}66.0 \\
(60.0-75.0)\end{array}$ & 0.36 \\
\hline \multicolumn{6}{|l|}{ Laboratory measurements } \\
\hline Hemoglobin, g/dl & $\begin{array}{c}13.6 \\
(12.5-14.7)\end{array}$ & $\begin{array}{c}14.8 \\
(14.0-15.4)\end{array}$ & $\begin{array}{c}13.8 \\
(12.8-14.6)\end{array}$ & $\begin{array}{c}12.2 \\
(10.9-12.7)\end{array}$ & $<0.001$ \\
\hline Sodium, mmol/l & $\begin{array}{c}140.0 \\
(137.0-141.0)\end{array}$ & $\begin{array}{c}140.0 \\
(137.0-141.0)\end{array}$ & $\begin{array}{c}140.0 \\
(138.0-141.0)\end{array}$ & $\begin{array}{c}138.5 \\
(137.0-141.0)\end{array}$ & 0.37 \\
\hline eGFR, $\mathrm{ml} / \mathrm{min} / 1.73 \mathrm{~m}^{2}$ & $\begin{array}{c}70.0 \\
(53.0-85.0)\end{array}$ & $\begin{array}{c}68.5 \\
(56.0-91.1)\end{array}$ & $\begin{array}{c}66.1 \\
(49.0-84.4)\end{array}$ & $\begin{array}{c}72.2 \\
(52.0-81.0)\end{array}$ & 0.60 \\
\hline NT proBNP, pg/ml & $\begin{array}{c}1025 \\
(283-2384)\end{array}$ & $\begin{array}{c}661 \\
(113-2384)\end{array}$ & $\begin{array}{c}595 \\
(204-2074)\end{array}$ & $\begin{array}{c}1777 \\
(1025-3738)\end{array}$ & 0.10 \\
\hline ePVS, \% & $\begin{array}{c}-20.6 \\
(-29.9--9.7)\end{array}$ & $\begin{array}{c}-33.0 \\
(-37.7--16.6)\end{array}$ & $\begin{array}{c}-26.9 \\
(-28.4--8.7)\end{array}$ & $\begin{array}{c}-12.8 \\
(-16.8-4.0)\end{array}$ & $<0.001$ \\
\hline \multicolumn{6}{|l|}{ LV function } \\
\hline LVSV index, $\mathbf{m l} / \mathbf{m}^{2}$ & $\begin{array}{c}31.4 \\
(19.3-50.6)\end{array}$ & $\begin{array}{c}30.3 \\
(19.5-47.8)\end{array}$ & $\begin{array}{c}31.6 \\
(18.8-48.8)\end{array}$ & $\begin{array}{c}35.7 \\
(20.9-69.2)\end{array}$ & 0.67 \\
\hline LAV index, $\mathbf{m l} / \mathbf{m}^{2}$ & $\begin{array}{c}47.7 \\
(33.4-62.3)\end{array}$ & $\begin{array}{c}44.2 \\
(28.5-52.4)\end{array}$ & $\begin{array}{c}48.9 \\
(33.8-62.3)\end{array}$ & $\begin{array}{c}53.3 \\
(36.6-65.5)\end{array}$ & 0.06 \\
\hline LVEF, \% & $\begin{array}{c}52.0 \\
(33.0-62.0)\end{array}$ & $\begin{array}{c}48.0 \\
(40.0-62.0)\end{array}$ & $\begin{array}{c}53.3 \\
(37.0-61.4)\end{array}$ & $\begin{array}{c}50.4 \\
(31.0-62.0)\end{array}$ & 0.78 \\
\hline LVEF $<40 \%, N(\%)$ & $26(33.3 \%)$ & $6(23.1 \%)$ & $8(30.8 \%)$ & $12(46.2 \%)$ & 0.20 \\
\hline LVEF $\geq 50 \%, N(\%)$ & $42(53.8 \%)$ & $12(46.2 \%)$ & $17(65.4 \%)$ & $13(50.0 \%)$ & 0.34 \\
\hline Global longitudinal strain, \% & $\begin{array}{c}-12.9 \\
(-18.4--8.6)\end{array}$ & $\begin{array}{c}-13.6 \\
(-18.0--8.6)\end{array}$ & $\begin{array}{c}-15.2 \\
(-19.2--9.8)\end{array}$ & $\begin{array}{c}-10.3 \\
(-16.9--7.4)\end{array}$ & 0.28 \\
\hline $\mathrm{E} / \mathrm{A}$ ratio $(\mathrm{N}=61)$ & $\begin{array}{c}0.9 \\
(0.7-1.6)\end{array}$ & $\begin{array}{c}0.9 \\
(0.6-1.5)\end{array}$ & $\begin{array}{c}0.9 \\
(0.7-1.9)\end{array}$ & $\begin{array}{c}1.0 \\
(0.8-1.8)\end{array}$ & 0.60 \\
\hline$e^{\prime}$ mean, $\mathrm{cm} / \mathrm{s}$ & $\begin{array}{c}6.5 \\
(4.5-8.5)\end{array}$ & $\begin{array}{c}6.8 \\
(5.0-9.5)\end{array}$ & $\begin{array}{c}6.5 \\
(5.0-9.0)\end{array}$ & $\begin{array}{c}6.5 \\
(3.5-7.0)\end{array}$ & 0.36 \\
\hline E/e' mean & $\begin{array}{c}12.5 \\
(9.3-18.3)\end{array}$ & $\begin{array}{c}10.4 \\
(8.4-14.7)\end{array}$ & $\begin{array}{c}13.1 \\
(9.4-18.5)\end{array}$ & $\begin{array}{c}15.5 \\
(11.1-22.6)\end{array}$ & 0.054 \\
\hline \multicolumn{6}{|l|}{ RV function } \\
\hline RAV index, $\mathbf{m l} / \mathbf{m}^{2}$ & $\begin{array}{c}25.4 \\
(19.5-34.4)\end{array}$ & $\begin{array}{c}27.6 \\
(19.6-34.1)\end{array}$ & $\begin{array}{c}24.8 \\
(19.3-35.6)\end{array}$ & $\begin{array}{c}25.6 \\
(19.5-31.2)\end{array}$ & 0.77 \\
\hline TAPSE, mm & $\begin{array}{c}22.8 \\
(18.0-25.3)\end{array}$ & $\begin{array}{c}22.5 \\
(19.0-25.0)\end{array}$ & $\begin{array}{c}23.5 \\
(18.0-30.0)\end{array}$ & $\begin{array}{c}21.5 \\
(18.0-24.0)\end{array}$ & 0.24 \\
\hline RV IVA, m/sec & $\begin{array}{c}1.4 \\
(0.9-2.1)\end{array}$ & $\begin{array}{c}1.4 \\
(0.9-1.7)\end{array}$ & $\begin{array}{c}1.7 \\
(1.1-2.2)\end{array}$ & $\begin{array}{c}1.2 \\
(0.8-2.1)\end{array}$ & 0.16 \\
\hline IVC dimension, mm & 13.0 & 12.0 & 14.5 & 12.5 & 0.54 \\
\hline
\end{tabular}


estimated PAPS, mmHg

Other parameters

LVEDP, mmHg

LV-PreA, mmHg (N=61)

Total B-Lines

$$
\begin{gathered}
(8.0-16.7) \\
34.0 \\
(26.0-45.0) \\
\\
16.0 \\
(12.0-22.0) \\
10.0 \\
(7.0-16.0) \\
3.0
\end{gathered}
$$

$(0.0-12.0)$

$$
\begin{gathered}
(6.0-16.7) \\
34.0 \\
(23.0-40.0) \\
\\
14.5 \\
(10.0-20.0) \\
8.5 \\
(5.0-10.0) \\
2.0 \\
(0.0-9.0)
\end{gathered}
$$

(9.5 - 20.0)

$$
35.0
$$

$$
17.0
$$$$
11.0
$$
4.0

$(0.0-19.0)$

* Sex specific tertiles indicate the tertiles derived from male and female separately.

M, male; F, female; COPD, chronic obstructive pulmonary disease; ACEi, angiotensin converting enzyme inhibitor; ARB, angiotensin receptor blocker; MRA, mineralocorticoid receptor antagonist; NYHA, New York Heart Association; BP, blood pressure; eGFR, estimated glomerular filtration rate; NT proBNP, N-terminal prohormone brain natriuretic peptide; ePVS, estimated plasma volume status; LVSV, left ventricular systolic volume; LAV, left atrial volume; LVEF, left ventricular ejection fraction; E/A, ratio of peak early and late diastolic velocities; e', mean value of early diastolic velocity at the septal and lateral sites of the mitral annulus; E/e', ratio of early mitral inflow velocity and mitral annular early diastolic velocity; RAV, right atrial volume; TAPSE, tricuspid annular plane systolic excursion; IVA, isovolumic acceleration; IVC, inferior vena cava; PASP, pulmonary artery systolic pressure; LVEDP, left ventricular end-diastolic pressure. 
Supplementary table 3. Multivariable Model for the Association of Clinical, Biological and Hemodynamic Parameters with Estimated Plasma Volume Status (Hakim formula)

\begin{tabular}{|c|c|c|c|c|}
\hline & \multicolumn{2}{|c|}{ Univariable model } & \multicolumn{2}{|c|}{ Multivariable model } \\
\hline & $\beta(95 \% C I)$ & p-Value & $\beta(95 \% \mathrm{CI})$ & p-Value \\
\hline \multicolumn{5}{|l|}{ Clinical parameters } \\
\hline Age, yrs (per 5 yrs) & $1.81(0.59-3.03)$ & 0.004 & - & - \\
\hline Male sex & $-3.01(-8.21-2.20)$ & 0.25 & & \\
\hline Body mass index, $\mathrm{kg} / \mathrm{m}^{2}\left(\right.$ per $\left.5 \mathrm{~kg} / \mathrm{m}^{2}\right)$ & $-6.07(-7.75--4.38)$ & $<0.001$ & $-6.07(-8.26--3.89)$ & $<0.001$ \\
\hline Hypertension & $-0.34(-5.54-4.85)$ & 0.90 & & \\
\hline Diabetes mellitus & $0.90(-5.10-6.90)$ & 0.77 & & \\
\hline Coronary artery disease & $2.41(-2.41-7.23)$ & 0.32 & & \\
\hline Heart failure & $4.19(-0.57-8.94)$ & 0.08 & - & - \\
\hline NYHA III+IV & $1.26(-4.19-6.72)$ & 0.65 & & \\
\hline Diastolic BP, mmHg (per 5 mmHg) & $-1.84(-3.63--0.06)$ & 0.043 & $-2.45(-4.22--0.68)$ & 0.008 \\
\hline \multicolumn{5}{|l|}{ Biological parameters } \\
\hline Sodium, mmol/l (per 5 mmol/l) & $-1.88(-5.20-1.45)$ & 0.26 & & \\
\hline eGFR, $\mathrm{ml} / \mathrm{min} / 1.73 \mathrm{~m}^{2}\left(\right.$ per $\left.5 \mathrm{ml} / \mathrm{min} / 1.73 \mathrm{~m}^{2}\right)$ & $-0.16(-0.75-0.43)$ & 0.59 & & \\
\hline Log NT proBNP & $1.91(-0.13-3.95)$ & 0.07 & - & - \\
\hline \multicolumn{5}{|l|}{ Left ventricular function } \\
\hline LVSV index, $\mathrm{ml} / \mathrm{m}^{2}\left(\right.$ per $\left.5 \mathrm{ml} / \mathrm{m}^{2}\right)$ & $0.27(-0.14-0.68)$ & 0.20 & & \\
\hline LAV index, $\mathrm{ml} / \mathrm{m}^{2}\left(\right.$ per $\left.5 \mathrm{ml} / \mathrm{m}^{2}\right)$ & $0.75(0.24-1.26)$ & 0.005 & 一 & - \\
\hline LV ejection fraction, \% (per $5 \%$ ) & $-0.10(-0.84-0.63)$ & 0.78 & & \\
\hline LV ejection fraction $<40 \%$ & $4.15(-0.90-9.20)$ & 0.11 & & \\
\hline Global longitudinal strain, \% & $0.22(-0.21-0.65)$ & 0.31 & & \\
\hline $\mathrm{E} / \mathrm{A}$ ratio & $-0.02(-2.88-2.85)$ & 0.99 & & \\
\hline E/e' mean & $0.32(0.06-0.59)$ & 0.02 & - & - \\
\hline \multicolumn{5}{|l|}{ Right ventricular function } \\
\hline TAPSE, mm & $-0.25(-0.68-0.18)$ & 0.25 & & \\
\hline RV IVA, m/sec & $-0.11(-2.37-2.16)$ & 0.93 & & \\
\hline IVC dimension, mm & $0.10(-0.32-0.52)$ & 0.64 & & \\
\hline estimated PAPS, mmHg (per $5 \mathrm{mmHg}$ ) & $0.59(-0.29-1.47)$ & 0.18 & & \\
\hline \multicolumn{5}{|l|}{ Others } \\
\hline LVEDP, mmHg & $0.05(-0.27-0.37)$ & 0.75 & & \\
\hline Total B-Lines & $0.15(-0.10-0.39)$ & 0.24 & & \\
\hline
\end{tabular}

NYHA, New York Heart Association; BP, diastolic blood pressure; eGFR, eGFR, estimated glomerular filtration rate; NT proBNP, N-terminal prohormone brain natriuretic peptide; LVSV, left ventricular stroke volume; LAV, left atrial volume; E/A ratio of peak early and late diastolic velocities; E/e', ratio of early mitral inflow velocity and mitral annular early diastolic velocity; RAV, right atrial volume; TAPSE, tricuspid annular plane systolic excursion; IVA, isovolumic acceleration; IVC, inferior vena cava; PASP, pulmonary artery systolic pressure; LVEDP, left ventricular end-diastolic pressure. 